r ScIDioc

\section{Dental Status Between Assisted Reproductive Technology And Natural Conceived Children: A Comparative Pilot Study}

Research Article

NorzaitiMohd Kenali ${ }^{1}$, Susi Sukmasari², Farah Natashah Mohd ${ }^{3 *}$, MohdSyazwanAididMohamad Basiri ${ }^{4}$, MohdFirdaus Lokhman ${ }^{5}$

${ }^{1}$ Lecturer, Paediatric Dentistry Unit, Kulliyyah of Dentistry, IIUM.

${ }^{2}$ Lecturer, Paediatric Dentistry Unit, Kulliyyah of Dentistry, IIUM .

${ }^{3}$ Lecturer, Special Care Dentistry Unit, Oral diagnosis and Oral Maxillofacial Surgery Department, Kulliyyah of Dentistry, IIUM.

${ }^{4}$ Final year dental students, Kulliyyah of Dentistry, IIUM

${ }^{5}$ Final year dental students, Kulliyyah of Dentistry, IIUM.

Abstract

Objectives: ART children were proven to have low birth weight and some birth defects. However, limited number of studies found concerning dental status of ART children. This research aimed to determine oral health practice and dental status between Assisted-Reproductive (ART) and Natural Conceived (NC) children.

Materials And Method: This cross-sectional study consisted of 34 subjects, 17 were ART children and 17 NC children as control. Intraoral examination was conducted and orthopantomogram (OPG) radiograph were obtained from the subjects. Any abnormalities of tooth development such as number and tooth colour were recorded. Oral hygiene practice such as tooth brushing frequency and supervision from the parents during tooth brushing were identified. Caries experience of both groups were recorded using dmft for deciduous teeth and DMFT for permanent teeth. Descriptive analysis, Bivariate analysis were done using Mann-Whitney's test and Spearman rho test.

Results: Most of the participants were girls (58.8\%) and majority were aged of $7-8$ years old (47.1\%). $70.6 \%$ of ART group used intra-uterine insemination (IUI) technique while $29.4 \%$ used in-vitro fertilization (IVF). There was one hypodontia case found in each group. Caries experience in primary teeth showed significantly lower in the ART group with $\mathrm{p}<0.05$.

Conclusions: There was a comparable case of hypodontia in ART and NC group. However, caries experience (dmft) of children in ART group was found significantly lower than NC group.

Keywords: Assisted Reproductive Technology; Dental Caries; Tooth Anomalies; Oral Hygiene Practice.

\section{Introduction}

Assisted reproductive technology (ART) is an alternative way in achieving pregnancy. It is a treatment of infertility. In-vitro fertilization (IVF) and intra-uterine insemination (IUI) are examples of many procedures that can be performed to treat infertility. IVF is an assisted reproduction done in fertilizing man's sperm and a woman's egg in a laboratory dish [1]. There are several indications for couples to undergo the IVF treatment such as tubal pathology, unexplained fertility, endometriosis, male infertility, hormonal disturbances, advanced maternal age, genetic abnormalities and recurrent pregnancy lost. The first child was born by IVF method is Louise Brown. She was born in 1978 at Oldham General Hospital, England. Her mother, Lesley Brown faced fallopian tubes blockage [2] .
Fertility problem is a worldwide issue thus the number of couples receiving ART was expanding globally [3]. According to the Ministry of Health Malaysia, about 300000 new partners seek fertility treatment in 2006 [4]. The success rates of IVF and IUI was varies. According to the results achieved by one of the fertility clinics in Kuala Lumpur (Metro Clinic) in 2014, the successful pregnancy resulting from IVF was $76.30 \%$. Meanwhile for IUI, ranges between $5 \%$ to $70 \%$ [3]. A report by International Committee for the Monitoring of Assisted Reproductive Technology, about eight million babies have been born by IVF method since 2018 [5].

However, the ART is not without a risk. The chances of obtaining a child with birth defect is higher compared to natural conceived by $1.8 \%$ such as genetic defects, low birth weight and preterm birth [6].

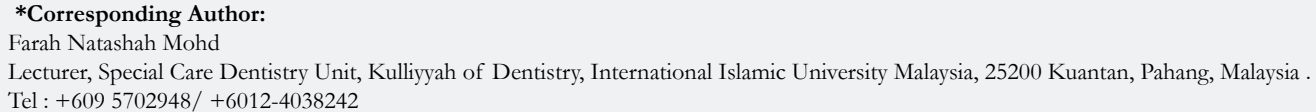

Citation: Norzaiti Mohd Kenali, Susi Sukmasari, Farah Natashah Mohd, M ohdSyazwan Aidid Mohamad Basir, Mohd Firdaus Lokhman. Dental Status Between Assisted Reproductive Technology And Natural Conceived Children: A Comparative Pilot Study. Int J Dentistry Oral Sci. 2021;8(7):3306-3310. doi: http://dx.doi.org/10.19070/2377-8075-21000674

Copyright: Farah Natashah Mohd ${ }^{\bullet}$ 2021. This is an open-access article distributed under the terms of the Creative Commons Attribution License, which permits unrestricted use, distribution and reproduction in any medium, provided the original author and source are credited. 
Dental status is the condition of soft or hard tissue in the oral cavity through intraoral clinical examination. The complete set of primary teeth is twenty and for permanent teeth is thirty-two. However, the number of teeth in the mouth varies, depending on the age of the patient, but the actual number of unerupted teeth can be read through radiograph. The abnormalities of the colour of the teeth could be due to extrinsic or intrinsic staining, the latter was more due to developmental defect, trauma or bacteria origin. Dental caries is a multifactorial disease, caused by bacteria mainly Streptococcus mutans and sugary food on tooth enamel. The colour and tooth structure of the carious tooth can be recorded by using decayed, missing and filled teeth index (DMFT) for permanent teeth and $\mathrm{dmft}$ index for primary teeth. Detrimental effects of caries are pain, swelling and fever. Thus, regular toothbrushing is a gold standard of mechanical cleansing to prevent dental caries. In younger children, supervision from adult during tooth brushing is important to maintain good oral hygiene [21].

Most studies had focused on the oral health of the couples who were obtained ART to conceive. Some studies found that there was a link between periodontal disease and infertility. It was mentioned that patient with periodontal problem having more time consuming to bear a child compared with patient without periodontitis [7-9]. A study conducted in India found there was no significant difference in enamel defect for both IVF and NC children. Apart from this the same researchers also did a study on the dental attrition between IVF children and NC children but no significant difference was found $[10,11]$.

There is lack of data regarding dental status among ART children compared to the NC children. This preliminary study is expected to give knowledge regarding the status of the teeth and their oral hygiene practice of the two groups.

The knowledge will be beneficial to health personnel as well as to the future parents regarding their future children resulted in ART procedures that may or may not be associated with the children's oral health condition.

\section{Objectives}

This research aimed to assess the dental status and oral health practice between ART group of children and NC children as well as to assess the association between their sociodemographicbackground with dental status.

\section{Materials And Method}

\section{Study Design}

This was a cross-sectional study by utilizing records of all patients attended to IIUM Fertility Centre and Polyclinic KOD IIUM via convenience sampling method.

\section{Ethical Consideration}

Ethical clearance was obtained from IIUM Research Ethics Committee (IREC) with reference number of IREC 761. All data regarding patient's identification and medical records were kept as confidential.

\section{Patient Selection}

The study took over as 1-year study from data collection to data analysis and interpretation which involved 34 subjects. Several inclusion criteria were made. As inclusion criterion for this study are:

(1) ART children from IIUM Fertility Centre records.

(2) Natural conceived children from the IIUM Polyclinic attendee records.

(3) Children with age range from 5-16 years old.

List of patients who underwent ART were received from IIUM Fertility Centre. Name of parents, address and their contact number were obtained from IIUM Fertility Centre. Only those who were born from 2008 to 2012 were selected. Out of 97 patients, only 17 responded and agreed to involve in this research. For NC children, the data were collected from Polyclinic Kulliyyah of Dentistry IIUM. Simple random sampling was applied to select the patients. Patient's files were retrieved from Polyclinic or Specialist clinic Kulliyyah of Dentistry (KOD) IIUM.

\section{Data Collection}

\section{Clinical Examination}

For ART patients, each of them was contacted via calls or texts. Upon verbal consent by the parents, appointment was made in KOD. Once registered, a written consent was obtained from the parents either mother or father. Their demographic data were recorded regarding their names, age, type of conceptual, medical history, dental history, and their parent's history were asked. Then, the subjects had a clinical examination by a paediatric dentistry specialist to check their dental caries experience, by using DMF-T or dmf-t scores. and any other tooth abnormalities such as supernumerary tooth, abnormal colour, shape or hypodontia.

For NC patient, random patients' files were selected in corresponding to ART patients' age. Then, their name, age, medical history, dental history and their DMF-T or dft scores and any dental anomalies were recorded.

\section{Radiographic Examination}

The patients were brought to Extraoral Radiographic Room for Orthopanthomagraph (OPG). Each OPG was examined via PlanmecaRomexis 2.8.0 to check for any dental anomalies such as hypodontia, supernumerary or impacted teeth. For normal patients, their OPG was checked via PlanmecaRomexis 2.8.0. The OPG report was given by the same specialist.

\section{Data And Statistical Analysis}

The data were analyzed using Statistical Package for Social Science (SPSS Inc, Chicago, IL) version 25.0. Descriptive statistics were computed for each study variable. To measure the association between dependent and independent variables, crosstab statistics were analysed. Mann-Whitney's test and Spearman rho test were used to analyse the data. The level of significance was set at $\mathrm{p} \leq 0.05$. 


\section{Results}

Table 1 illustrates the participants' sociodemographic background. The mean age of ART and NC methods are $7.18 \pm 1.59$ and $5.94 \pm 1.29$ respectively. Both groups were dominated by females. Nearly half of the ART children $(47.1 \%)$ have underlying medical illness whereas only $29.4 \%$ of NC children having medical problem.

Table 2 shows that more than $60 \%$ of the participants in both groups brush their teeth twice daily and $90 \%$ of them being supervised by their parents during tooth brushing. However, it is shown that the median $\mathrm{dmft}$ score for $\mathrm{NC}$ group is more than three times lower compared to the other group. As for dental anomalies, both groups show a comparable case.

Table 3 shows that there is significant difference with $\mathrm{p}<0.05$ between ART and NC group in $\mathrm{dmft}$ score. Nevertheless, there are no association between the $\mathrm{dmft}$ score with other factors such as age, gender, number of siblings, tooth brushing frequency and supervision of tooth brushing by parents

\section{Discussion}

\section{Sociodemographic Background}

The mean age of ART and NC groups were 7 and 6-years-old respectively. The age of the children in the ART group were selected by convenience sampling, thus the NC group were matched with ART group as closed as possible. However, both groups were still comparable since all the children presented with deciduous teeth and there was no missing tooth noted. The median number of siblings in ART group was only 2. This was found by similar study by Righarts et al (2017) mentioned that among those who had primary infertility and resolved their infertility, $63.8 \%$ had at least one additional child [12]. It is known that they were having difficulties in pregnancy for years, thus majority of the ART parents who used these techniques to have children were in their middle aged. The largest cohort of women receiving ART treatments were those between 35 and 40 years, with usage declining after the age of $40[13,14]$.

\section{Medical And Dental Status}

Couples who have difficulty in bearing children were due to re-

Table 1: Sociodemographic background

\begin{tabular}{|c|c|c|}
\hline Variables & ART (\%) & NC (\%) \\
\hline $\mathrm{N}$ & 17 & 17 \\
\hline Age (mean \pm SD) & $7.18(1.59)$ & $5.94(1.29)$ \\
\hline \multicolumn{3}{|l|}{ Gender } \\
\hline Male & $7(41.2)$ & $6(35.3)$ \\
\hline Female & $10(58.8)$ & $11(64.7)$ \\
\hline \multicolumn{3}{|l|}{ Number of siblings } \\
\hline (median: IQR) & $2(1)$ & $3(1)$ \\
\hline \multicolumn{3}{|l|}{ Current medical illness } \\
\hline Yes & $8(47.1)$ & $5(29.4)$ \\
\hline $\mathrm{No}$ & $9(52.9)$ & $12(70.6)$ \\
\hline
\end{tabular}

Table 2: Oral health behaviour and dental status

\begin{tabular}{|c|c|c|}
\hline Variables & ART n (\%) & $\mathrm{NCn}(\%)$ \\
\hline Tooth brushing frequency & $\mathrm{n}=14$ & $\mathrm{n}=16$ \\
\hline Once daily & $5(35.7)$ & $5(31.3)$ \\
\hline Twice daily & $9(64.3)$ & $11(68.7)$ \\
\hline Supervisionof tooth brushing by parents & $\mathrm{n}=14$ & $n=15$ \\
\hline Yes & $13(92.9)$ & $14(93.3)$ \\
\hline No & $1(7.1)$ & $1(6.7)$ \\
\hline dmft (median;IQR) & $3.00(10.00)$ & $11.00(4.00)$ \\
\hline DMFT & 0 & 0 \\
\hline Dental anomalies & $\mathrm{n}=17$ & $\mathrm{n}=17$ \\
\hline NumberYes & $1(5.9)$ & $1(5.9)$ \\
\hline No & $16(94.1)$ & $16(94.1)$ \\
\hline \multicolumn{3}{|l|}{ Shape and colour } \\
\hline Yes & 0 & 0 \\
\hline No & 17 & 17 \\
\hline
\end{tabular}


Table 3: Association between dmft status and sociodemographic.

*Mann-whitney test

†Spearman rho test

\begin{tabular}{|c|c|c|}
\hline Variables & \multicolumn{2}{|c|}{ Oral health status (total dmf-t score) } \\
\hline & Mediandmft (IQR) & P value \\
\hline Conceiving methods & $3.00(10.00)$ & \\
\hline ART & $11.00(4.00)$ & $0.002^{*}$ \\
\hline NC & & \\
\hline Gender & $10.0(10.0)$ & \\
\hline Female & $7.00(11.0)$ & $0.664^{*}$ \\
\hline Male & $7.06(1.43)$ & $0.744+$ \\
\hline Age (Mean SD)b & $3.00(1.00)$ & $0.582+$ \\
\hline Number of siblings & & \\
\hline Brushing teeth & $12.00(8.00)$ & \\
\hline Once daily & $9.00(8.00)$ & $0.166^{*}$ \\
\hline Twice daily & & \\
\hline Supervision of toothbrushing \\
by parents & $9.00(10.00)$ & \\
\hline Yes & $11.50(0.00)$ & \\
\hline No & & \\
\hline
\end{tabular}

productive diseases and having this ART to have babies. Hence, the medical condition of ART children is far more concern than in NC group of children. Research showed that children who were born using ART technique were likely to having medical illness such low birth weight, prematurity and birth structural defect especially among multiple pregnant mothers [15]. Other medical illnesses were including physical abnormalities such as musculoskeletal disease and oesophageal defect[15]. However, when restricted to singletons of ART children, they had a similar outcome for many health conditions as their spontaneously conceived peers [16]. In this study, all ART children were physically in perfect condition, however $20 \%$ of them were having medical illness including pneumonia and asthma. However, there was no significant different as compared in NC children. This was an agreement with systematic review recently conducted by Christina Bergh 2020 stated that there was limited data regarding the health of ART children, such as cerebral palsy, cardiovascular function, diabetes and respiratory function[16]. As such, conclusion could not be made whether it was due to the environment or ART itself. Whereas neurodevelopmental health and school performance in children conceived by ART and spontaneously conceived children were reported similar [17].

Since all the numbers of teeth found orally was completed for the age, there was one radiographic finding of missing tooth (hypodontia) identified in both groups which comprised of $5.9 \%$. This finding was supported by Khalaf et al (2020) stated that the overall prevalence of hypodontia was found to be $6.4 \%$ [18]. However, other study reported; excluding third molars, the reported prevalence of hypodontia ranges from 1.6 to $36.5 \%$, depending on the population studied [19]. A systematic review found that the most commonly affected teeth were mandibular second premolars followed by maxillary lateral incisors and maxillary second premolars[18]. The finding in this study was missing of the upper permanent lateral incisor for ART group and lower permanent incisor for NC group. This finding suggests the missing tooth in both groups were comparable and could not be associated with the ART procedure itself. However, further study needs to be conducted regarding the causal factors of these missing teeth which is beyond of this study.

\section{Oral Hygiene Practice And Caries Status}

NC group brushed their teeth twice a day as well as ART group as recommended by England guideline 2018[20] (Table 2). Due to lack of knowledge and motor coordination during toothbrushing, children need supervision by their parents or guardian during tooth brushing that will give better outcome. Children with optimum oral health will have less dental problem such as gingivitis and dental caries. As claimed by both groups in this study almost all of parents claimed they did monitor their children during tooth brushing. However, the methods of supervision were not well described in this study. A local study found that there was no association between types of supervision and oral hygiene level of the children, as well as the supervision methods by parents during tooth brushing and their dmft status [21]. However, in contrary current study found there was a significant difference in ART group with $(\mathrm{p}<0.05)$ in which they have lower $\mathrm{dmft}$ score (Table 3). This could be explained by parents of ART children who were claimed to be more protective and caring towards their children and these babies were more appreciated [22]. This serves as an advantage in ART group for monitoring the child's oral hygiene more effectively and having less caries lesion.

Caries experience in both permanent and primary teeth and $\mathrm{DMFT} / \mathrm{dmft}$ index was calculated. However, DMFT index (for permanent teeth) scored 0 means all the permanent teeth were caries free in both groups. This finding is in agreement with Bourgeois (2014) where the percentage of DMFT was 0 and the score was slightly increased among primary school children and reduced 
with aged [23]. However, as in primary teeth, the dmft score (median) for ART group was three times lower as compared with in NC group (Table 2). Although ART group have lower dmft score (Table 3), there was no association found for both tooth-brushing frequency and supervision with $\mathrm{dmft}$ score. This finding could be due to dental caries is a multi-factorial disease which involves local and systemic factors. Local factors such as saliva, oral microbes, structure of the teeth, diet and time [24]. Whereas systemic factors which include fluoride intake and medical status of the child [24]. The American Association of Paediatric Dentistry guideline also mentioned that socioeconomic factors also play a role in dental caries disease [24]. Therefore, it could be stipulated that the parents of ART group in this study have strong socioeconomic status where they may have good education with stable economy. Thus, the dmft score of their children is much lower compared to NC group. The findings also showed that dmft score in ART group was lower than the mean of $\mathrm{dmft}$ reported by National Oral Health Survey of Preschool Children (NOHPS) 2015 which was 4.8. This could be due to NC patients were selected from dental clinic who came for treatment.

Since this is a pilot study, further study needs to be conducted to assess the root cause of caries among children in both categories

\section{Limitations}

Although this research has reached its aim, there are several limitations while conducting this research. Patients' contact numbers cannot be reached and thus lead to difficulty in reaching the patients. The other limitation is the list of ART patient only come from one fertility centre which was in IIUM fertility centre.

\section{Recommendations}

Therefore, from this research, there are several recommendations to improve the result for future research. First, to involve multiple fertility centres in Malaysia in order to increase sample size. Thus, the result will be more significant and representing the Malaysian population. Next, data for the normal patients should be new patients, those who never received any dental treatment to avoid bias result in data analysis. More socioeconomic family background should be assessed, thorough dental assessments could be done such as BPE index, plaque score, saliva and soft tissues.

\section{Conclusion}

Caries experience was found to be lower in ART children in this study with no significant findings between their dental status and their sociodemographic background. This showed that parents of children that were born using ART may give more attention to their children's oral health.

\section{Funding Sources}

This study is funded by Fundamental Research Grant Scheme (FRGS/1/2019/SKK14/UIAM/03/4)

\section{References}

[1]. Toner JP, Coddington CC, Doody K, Van Voorhis B, Seifer DB, Ball GD, et al. Society for Assisted Reproductive Technology and assisted reproductive technology in the United States: a 2016 update. Fertil. Steril. 2016 Sep 1;106(3):541-6.

[2]. Kamel RM. Assisted reproductive technology after the birth of louise brown. J ReprodInfertil. 2013 Jul;14(3):96-109.Pubmed PMID: 24163793.

[3]. BHD MIS. Success rate: METRO IVF SDN BHD

[4]. Ahmad Murad Z, Zailin Shah Y, Mansor S, Ahmad Irfan IH, Abdullah L. Is Assisted Reproductive Technique Shari'aa-compliant? A Case Study at a Fertility Centre in Malaysia. IIUM Int. Med. J. Malays. 2020;13(2).

[5]. S B. More than eight million babies have been born from IVF since the world's first test tube baby in the UK in 1978, reveal experts. Daily Mail. 20183 July.

[6]. Iowa. Uo. Slight Increased Risk Of Major Birth Defects Associated With IVF. ScienceDaily. 200530 November.

[7]. Hart R, Doherty DA, Pennell CE, Newnham IA, Newnham JP. Periodontal disease: a potential modifiable risk factor limiting conception. Hum Reprod. 2012 May;27(5):1332-42.Pubmed PMID: 22362927.

[8]. Khanna SS, Dhaimade PA, Malhotra S. Oral Health Status and Fertility Treatment Including IVF. J ObstetGynaecol India. 2017 Dec;67(6):400404.Pubmed PMID: 29162952.

[9]. Nwhator SO, Opeodu OI, Ayanbadejo PO, Umeizudike KA, Olamijulo JA, Alade GO, et al. Could periodontitis affect time to conception?. Ann Med Health Sci Res. 2014;4(5):817-22.

[10]. Kar S, Sarkar S, Mukherjee A. Prevalence of dental attrition in in vitro fertilization children of West Bengal. J Hum Reprod Sci. 2014 Jan;7(1):34-40. Pubmed PMID: 24829529.

[11]. Kar S, Sarkar S, Mukherjee A. Prevalence and Distribution of Developmental Defects of Enamel in the Primary Dentition of IVF Children of West Bengal. J ClinDiagn Res. 2014 Jul;8(7):ZC73-6.Pubmed PMID: 25177644.

[12]. Righarts AA, Gray A, Dickson NP, Parkin L, Gillett WR. Resolution of infertility and number of children: 1386 couples followed for a median of 13 years. Hum Reprod. 2017 Oct 1;32(10):2042-2048.Pubmed PMID: 28938738

[13]. Assisted Reproductive Technology. ART Surveillance and Research Team 4770 Buford Highway, N.E.; Mail Stop F-74; Atlanta, GA 30341-3717. 2015 [cited 7/2/2020]. Available from:

[14]. Shilpa G, Gokhale N, Mallineni SK, Nuvvula S. Prevalence of dental anomalies in deciduous dentition and its association with succedaneous dentition: A cross-sectional study of 4180 South Indian children. J Indian SocPedodPrev Dent. 2017 Jan-Mar;35(1):56-62.Pubmed PMID: 28139484

[15]. Hart R, Norman RJ. The longer-term health outcomes for children born as a result of IVF treatment: Part I--General health outcomes. Hum Reprod Update. 2013 May-Jun;19(3):232-43.Pubmed PMID: 23449642.

[16]. Bergh C, Wennerholm UB. Long-term health of children conceived after assisted reproductive technology. Ups. J. Med. Sci. 2020 Apr 2;125(2):1-6.

[17]. Pinborg A. Short- and long-term outcomes in children born after assisted reproductive technology. BJOG. 2019 Jan;126(2):145-148.Pubmed PMID: 30120870.

[18]. Khalaf K, Miskelly J, Voge E, Macfarlane TV. Prevalence of hypodontia and associated factors: a systematic review and meta-analysis. J. Orthod. 2014 Dec 1;41(4):299-316

[19]. Al-Ani AH, Antoun JS, Thomson WM, Merriman TR, Farella M. Hypodontia: an update on its etiology, classification, and clinical management. BioMed Res. Int. 2017;2017:9378325.

[20]. Duxbury JT, Catleugh MA, Davies PRM, Davies DGM, Bartlett D, Harley K. Delivering Better Oral Helath: an evidence-based toolkit for prevention. In: Department of Health PHE, editor.: PHE.2017:100.

[21]. Maw T, NA MY, NB NS. Supervision methods in tooth brushing by mothers on their children in relation to the caries rate among the mothers and their children. Mater. Today. 2019 Jan 1;16:2374-9.

[22]. Crespo E, Bestard J. Psychosocial needs of women and their partners after successful assisted reproduction treatment in Barcelona. Reprod. Biomed. Soc. Online. 2016 Dec 1;3:90-9.

[23]. Bourgeois DM, Llodra JC. Global burden of dental condition among children in nine countries participating in an international oral health promotion programme, 2012-2013. Int Dent J. 2014 Oct;64Suppl 2:27-34.Pubmed PMID: 25209648.

[24]. Caries-risk Assessment and Management for Infants, Children, and Adolescents. AAPD. 2020. 